\author{
Economics Working Paper Series
}

2019/019

\title{
Internet Usage and the Cognitive Function of Retirees
}

Colin P. Green, Likun Mao and Vincent O’Sullivan

The Department of Economics

Lancaster University Management School

Lancaster LA1 4YX

UK provided that full acknowledgement is given. 


\section{Internet Usage and the Cognitive Function of Retirees}

Colin P. Green*, Likun Mao** and Vincent O'Sullivan***

ABSTRACT: Cognitive decline amongst older people is associated with poor health and lower quality of life. Previous studies demonstrate that retirement is a particularly critical period for cognitive decline and highlight the importance of post-retirement behaviours. Using longitudinal data from the Survey of Health, Ageing and Retirement in Europe, this study examines the effect of information technology usage on cognitive function, focusing on one specific form: internet usage. We demonstrate that post-retirement internet usage is associated with substantially higher scores on cognitive tests. To address the endogenous relationship between cognitive function and IT usage, we use pre-retirement computer exposure as a source of exogenous variation. Our IV results suggest smaller but still substantial moderating effects of IT usage on the cognitive decline of retirees. These results are concentrated amongst people who worked in middle-skill occupations that experienced largescale computerisation. More broadly, our results suggest a causal effect of computer usage on the cognitive function of retirees.

KEYWORDS: Cognitive function; internet; computers

JEL CODE: J14 Economics of the Elderly;

* Norwegian University of Science and Technology

** The Irish Longitudinal Study on Ageing

*** Lancaster University

Corresponding Author: Likun Mao, The Irish Longitudinal Study on Ageing, Trinity College Dublin, Dublin 2, Republic of Ireland. Email: lmao@tcd.ie.Tel: 0035318961000. 


\section{Introduction}

Across developed economies, the share of older people in the population is increasing. Furthermore, more people are living substantially beyond retirement age, even while these retirement ages have been rising. Previous research has highlighted that retirement from the workforce is a critical period for cognitive function (Rohwedder and Willis, 2010; Bonsong et al, 2012; Mazzonna and Peracchi, 2012; Celidoni et al, 2017; Atalay et al, 2019). It is well-known that cognitive function declines with age, and that cognitive function predicts a range of key health outcomes amongst older people. Atalay et al (2019) further demonstrate how certain behaviours, particularly mental activities, can have a moderating effect on post-retirement cognitive decline. Related to this, other studies have suggested a role of various forms of information technology in promoting behaviours that are protective of cognitive function. In practice, however, little is known about the relationship between IT usage and cognitive function over larger populations and the existing evidence cannot typically be interpreted causally. Our study returns to this issue and aims to provide estimates of the effect of a particular form of IT usage, internet usage, on the cognitive function of older people. We do this using a large, multi-country longitudinal dataset, and we adopt empirical strategies that provide estimates which we argue can be interpreted causally.

Why might IT usage affect the cognitive function of older people? A range of potential benefits from computer usage have been highlighted such as the facilitation of routine tasks, access to information, entertainment, social connection, and mental stimulation, all of which have the potential to improve quality of life (Czaja et al., 1993, 2001; Jones and Bayen 1998; McConatha et al., 1994). The potential for computers to affect cognitive function has motivated a series of small scale experimental studies, primarily in psychology, to assess the effect of computer and internet usage on various outcomes such as loneliness, depression, physical functioning, and general life satisfaction (White et al., 2002; Shapira et al., 2007; Slegers et al., 2008, 2009). In general, these studies have found no relationship between measures of computer competency, computer usage, and well-being. However, these results are difficult to interpret and generalise because of the non-random computer usage of older people, because of a lack 
of pre-study controls for personal characteristics salient for cognitive function, and because these studies often utilise convenience samples drawn from older people living in community dwellings or nursing homes.

A related body of literature uses larger cross-sectional datasets to examine conditional associations between computer usage and life outcomes of older people. This literature has found mixed results. For instance, Lelkes et al., (2012) examines the European Social Survey and report a positive and statistically significant association between regular internet usage and life satisfaction after controlling for many personal characteristics. Similar associations have been found using U.S. datasets such as the Health and Retirement Study (HRS) and Midlife in the United States (MIDUS) (Tun and Lachman 2012; Heo et al., 2015). On the other hand, Elliot et al., (2014) found no association between computer usage and mental health using the National Health and Aging Trends Study for the US.

It has been widely discussed that computer-based activities might influence many aspects of older people's cognitive function such as attention, memory, spatial abilities, and problem solving (see Rogers et al., 2005). But relatively few studies have focused explicitly on the effect of computer usage on the cognitive function of older people. Earlier studies showed a positive effect of computer-based interventions on cognitive function (McConatha et al., 1994). However, Slegers et al., (2009), again in a small-scale experimental setting, found no effect of a training program and subsequent computer usage on cognitive function. In contrast, evidence from larger samples suggest a positive association between computer usage and cognitive function across adulthood when conditioning on a range of controls for personal characteristics (Tun and Lachman 2012; Slegers et al., 2012). Overall, although there is a widespread belief that computer usage improves older people's cognitive function, the current literature provides mixed evidence.

The critical challenge in identifying the causal effect of computer usage on cognitive function is the endogenous nature of computer usage. The incidence and frequency of computer usage among older people reflects a range of factors that, themselves, are likely to be related to cognitive function. In the 
absence of an empirical strategy to address this endogeneity, it is unwise to interpret statistical associations between computer usage and cognitive function causally. For instance, omitted or inaccurately measured factors such as wealth and income are likely to influence both cognitive function and computer usage. ${ }^{1}$ Likewise, there is a clear potential for reverse causality between cognitive function and computer usage.

We estimate the effect of computer usage on the cognitive function of retirees using a sample drawn from a large longitudinal dataset, the Survey of Health, Ageing and Retirement in Europe (SHARE). Partly due to measurement issues in the data, we focus on a particular form of IT usage, internet usage. We focus on a specific sample of those who have been retired since 2004, and focus on their cognitive function in 2013. Our choice of sample has two advantages. First, it reduces the interconnections between computer usage, retirement decisions, and cognitive function (Friedberg 2003; Banks et al., 2010; Bonsang et al., 2012; Mazzonna and Peracchi 2012). Second, the retirees in this specific sample embarked on careers during the period before the general introduction of workplace computers that occurred from the 1980s onwards, and retirees in the sample typically retired before computers became ubiquitous in workplaces. The timing of the computerization of work places motivates our instrumental variable strategy, where we rely on differential rates of computerization that occurred during these individuals' working lives but are unlikely to have been a feature of their original occupational choice. We use this within-career variation in pre-retirement computer usage as a source of exogenous variation in the likelihood of post-retirement internet usage. Variation in pre-retirement computer usage, in practice, proves to be a highly relevant instrument, and we investigate the robustness of our results to potential violations in the exclusion restriction. We demonstrate that post-retirement internet usage leads

\footnotetext{
${ }^{1}$ A range of research in gerontology and psychology attempts to explain the determinants of computer usage among older people (e.g. Zheng et al., 2015; Silver 2014). Education, income, health, and prior computer experience are significantly predictive of computer usage among older people. Similarly, a mixture of qualitative and quantitative studies about the attitudes and perceptions of computer and internet usage among older people suggests that barriers to usage include the cost of equipment, learning difficulties, sceptical attitudes towards computers, lack of social connections, and physical and cognitive problems (Gatto et al.,2008; Lee et al.,2011).
} 
to marked reductions in the rate of decline of cognitive function among retirees. This positive effect of internet usage on cognitive function is seen across a range of sub-group analyses and model specifications. Together, this evidence suggests marked roles for IT access and behaviours in retirement in reducing the rate of cognitive decline.

In the next section, Section 2, we describe our data. In Section 3, we discuss our model. In Section 4, we present our main results. In Section 5, we present our robustness checks. Finally, in Section 6, we summarize and discuss our findings.

\section{Data}

Our data are drawn from the Survey of Health, Ageing and Retirement in Europe (SHARE), a large longitudinal pan-European study that collects information about health, employment history, and the socio-economic status of older people. People aged fifty and older were eligible to participate in SHARE when it started in 2004; thus, the youngest people in the sample were born in 1954 . We restrict our sample to participants observed in the first (2004), fourth (2011), and fifth (2013) waves of SHARE because these waves contain the information necessary for our analysis. For example, the first wave contains detailed information about the previous occupations of the participants. While in the fourth and fifth waves, participants were asked about internet usage, computer skills, and computer (or a tablet) usage at their current job or their final job before retirement. ${ }^{2}$ To reduce concerns about the endogeneity of retirement with respect to cognitive function, we restrict our sample to retirees only. Specifically, we restrict our sample to those who retired before the first wave of SHARE in 2004 and who did not later re-join the workforce. ${ }^{3}$ Our final sample consists of 3798 older people from across ten European

\footnotetext{
${ }^{2}$ Specifically, participants are asked "'During the past 7 days, have you used the internet, for emailing, searching for information, making purchases, or for any other purpose at least once?". The question about computer usage in the final job asks, "Did your last job before retiring require using a computer?" where a computer could be a PC or a tablet. This question is only asked if participants had retired.

${ }^{3}$ Appendix Table A1 enumerates the attrition between waves of SHARE and also shows the size of our sample relative to the entire sample in SHARE. As shown in Table A1, we also excluded participants in SHARE younger than fifty. These people were interviewed in SHARE because their partners were older than fifty. We excluded this younger group from our sample because trends in their cognitive function might be quite different from the over fifties. Finally, we excluded participants with missing values for the variables used in our analysis.
} 
countries: Austria; Belgium; Denmark; France; Germany; Italy; the Netherlands; Spain; Sweden; and Switzerland.

Our main outcome of interest is cognitive function measured at Wave 5 of SHARE in 2013. In SHARE, there is a range of measures of cognitive function relating to different aspects such as orientation, vocabulary, numeracy, verbal memory, etc. We focus on the word recall test in which older people are told a list of ten words and are then asked to recall the words immediately and then again after a delay of five minutes. While our main analysis focuses on this outcome, in additional analysis, we also examined alternative measures of cognitive function. From Table 1, we can see that the average number of words recalled was 3.11. This was a decrease from 2011, when the average number of words recalled was 3.27 .

\section{INSERT TABLE 1}

The aim of our study is to examine whether computer usage among older people affects their cognitive function. In Table 1 , we can see that $27 \%$ of older people used the internet during the past seven days. For these people, it is less likely that their internet usage is through using a smartphone or other mobile device. For instance, in 2012/2013 nearly 70\% of older people in the UK report using a desktop or laptop computer as their device to access internet (Matthews and Nazroo, 2015). From Table 1 , we can also see that, on average, $26 \%$ of our sample used a computer in their final job before retirement. The relationship between pre-retirement computer usage and post-retirement internet usage forms the basis of our instrumental variable strategy that we discuss in the next section.

\section{INSERT FIGURE 1}

Figure 1 displays a range of patterns in both post-retirement internet usage and computer usage in the final job before retirement. It shows that the proportion of internet users decreases with age, cognitive function, and years since retirement. We can also see that the proportion of those who used a computer in their final job before retirement increases along the distribution of cognitive function, while 
decreasing with age and years in retirement. In relation to the income distribution, there is a "U"-shaped relationship between position in the distribution and internet usage. Usage is lowest among the second quartile. The frequency of internet usage in the ten European countries in our sample also varies: no more than $10 \%$ report internet usage in Italy, but the figure is over $60 \%$ in Spain although both countries have lower than average scores on the recall test. ${ }^{4}$

Table 1 also shows the descriptive statistics of the other covariates used throughout the analysis. In terms of life history, the average person in the sample was 77.2 years old in 2013 ; hence, they were born during the mid-1930s. On average, they attended full-time education for 9.74 years. By Wave 5 of SHARE in 2013, they had been retired for an average of 17.68 years; hence they had retired during the early/mid-1990s. Nearly one fifth of the sample never worked (predominantly women). In terms of household characteristics, $63 \%$ of the sample were married or cohabiting, $26 \%$ were widows or widowers, and the remainder were single or divorced/separated. On average, there were 1.8 people in each household. $10 \%$ lived in a large city, $30 \%$ lived in rural areas, and the remainder lived in towns or suburbs. $72 \%$ owned their own home, and just a tiny fraction, less than $1 \%$, lived in a nursing home. The average annual income was $€ 21,384$ after adjusting for differences in prices between countries. The descriptive statistics indicated poor health and health behaviours among people in the sample. For example, average Body Mass Index was 26.65, and the average person visited their doctor 8.5 times. $86 \%$ of the sample had a chronic disease. $19 \%$ were physically inactive; $10 \%$ had drank more than two glasses of wine or equivalent each day; and $42 \%$ were daily smokers.

The final two columns of Table 1 show the difference in the means of these variables between those who use the internet versus those who do not. On average, internet users can recall 1.5 extra words on the recall test compared to non-internet users. However, internet users are also clearly different in other characteristics compared to non-users. They are more likely to be male, younger, better educated, to have always worked, and have been retired for a shorter period. Furthermore, internet users appear to be

\footnotetext{
4 See Appendix Table A2 for more detail.
} 
in better health, although they drank and smoked more during their lives. Most of these differences are statistically significant at standard levels. These differences motivate our multivariate analysis that aims to control for these observable differences. But these differences also suggest that unobservable factors influence internet usage; thus, we the need for an empirical strategy to address this.

\section{Methodology}

For our main estimates, we estimated the following value-added education production function:

$$
Y_{i t}=\alpha_{1} Y_{i t-1}+\gamma \text { Internet }_{i t}+\alpha_{2} X_{i t}+\varepsilon_{i t}
$$

In the fourth and fifth waves of SHARE, people were tested in word recall, immediate and delayed, and numeracy. Hence $Y_{i t}$ is cognitive function measured at time $t$ (at the fifth wave of SHARE in 2013) for individual $i$. Initially, we focus on the raw score and the standardized score of the delayed recall test. ${ }^{5}$ In our main estimates, we adopt a specification where we include an lagged measure of cognitive function, $Y_{i t-1}$, measure at the fourth Wave of SHARE in 2011. We assume this declines with age at a rate of $\alpha_{1}$. Introducing this lagged measure helps to condition on past confounding inputs into cognitive function, including effects of past computer usage. In additional estimates, we examine the robustness of our results to alternative functional forms. Internet ${ }_{i t}$ is a binary variable indicating whether an individual used the internet for e-mailing, searching for information, shopping, or for any other purpose at least once during the seven days before the survey. Thus $\gamma$ is the main parameter of interest. $X_{i t}$ is a vector of individual level characteristics used to control for demographics, life history, health status, and household conditions. A full list of these controls are included as notes to the main tables of estimates (see, for instance, Table 2). The demographic and life history variables include gender, age, country of survey, years of education, and years since retirement. The measures of health status are Body Mass Index, the number of visits to a doctor per year, whether the respondent has long-term chronic diseases, whether the respondent drinks more than two glasses of wine or equivalent every day, and whether the

\footnotetext{
${ }^{5}$ As an alternative, we could estimate (1) using a log transformation of the dependent variable, but this transformation would result in the loss of 831 observations where individuals could not recall any words.
} 
respondent ever smoked every day. The measures of household characteristics were marital status, household size, living in urban, rural areas or a town, house ownership, living in a nursing home, and annual household income. ${ }^{6}$ One concern with a number of these variables is that they themselves may be a function of internet access and / or prior cognitive function. In this way, they may constitute 'bad controls' (Angrist and Pischke, 2008). In the empirical analysis, we examine the robustness of our results to the inclusion of controls that could, conceivably, be outcomes themselves.

Non-random variation in internet access and usage means that $\gamma$ cannot be readily interpreted as a causal effect. Unobservable factors that influence internet usage are likely to also influence the rate of cognitive decline. Additionally, there could be feedback between cognitive function and internet usage. For example, those with higher rates of cognitive decline might be less likely to use the internet. These problems motivate our use of an instrumental variable strategy. We rely upon individuals' work history, motivated by the non-uniform computerization of occupations that occurred from the 1980s onwards, as documented in a large literature (see for instance, Autor et al., 1998, 2003, 2015), as a source of variation in post-retirement internet usage. ${ }^{7}$ The intuition behind our strategy follows from two main observations. First, those in the SHARE sample began working during the 1950s and 1960s, long before the computerization of workplaces that occurred from the 1980s onwards. Hence, these people are likely to have made important career decisions before expectations of computerisation could reasonably have been formed. ${ }^{8}$ This computerisation, while not random, was unevenly spread across the distribution of jobs. Thus, we observe variation in work-life exposure to computers which is likely to affect postretirement computer usage.

Our Instrumental Variable strategy is to estimate the following set of equations:

\footnotetext{
${ }^{6}$ In our main specification, the measure of income is a multi-stage imputed measure obtained by an aggregation at the household level of all individual income components. Additional information on the imputation procedure can be found in De Luca et al.,(2015).

${ }^{7}$ As noted by Bresnahan (1999), the diffusion of computer technology started to increase after the late 1950s. After which, personal computers (e.g. Apple II in 1977, IBM in 1981) emerged and spread.

${ }^{8}$ Also, it is unlikely that these older people, or most of them, would have trained in computing while in school or university.
} 


$$
\begin{aligned}
& Y_{i t}=\alpha_{1} Y_{i t-1}+\gamma \text { Internet }_{i t}+\alpha_{2} X_{i t}+\varepsilon_{i t} \\
& \text { Internet }_{i t}=\beta_{1} Y_{i t-1}+\vartheta \text { Exposure }_{i t}+\beta_{2} X_{i t}+\mu_{i t}
\end{aligned}
$$

The most important feature of equations $(2 a)$ and $(2 b)$ is that, when combined with our control for prior cognitive function, our exclusion restriction is that pre-retirement computer usage does not directly influence post-retirement cognitive decline. Controls for prior cognitive function along with controls for education mean that exposure should not be a function of, for instance, the skill level of the worker. Later, we demonstrate that our IV results are concentrated amongst workers in middle-skill occupations, the group where routine tasks have been shown to be most concentrated. These results fit with the idea that it is these middle-skill workers who had unexpected shocks to computer usage during their working life. We also provide descriptive information showing the uneven spread of computerisation across industries and occupational groups.

In practice, the main form of computer exposure examined in this study is dictated by data availability. Specifically, we examine whether the individual used a computer in their final preretirement job as our source of variation in post-retirement internet usage. In Section 5.1, we explore the robustness of our results to alternative versions of this instrumental variable, which are also linked to variations in workplace exposure, as well as examining likely sources of violation of the exclusion restriction. In addition, we estimate analogues of (2a) and (2b) where we adopt alternative strategies to modelling the relationship between current and prior cognitive function.

A final concern is the difference in retirement age patterns across individuals. Our main strategy is to focus solely on those who retired before 2004 and did not return to work. Hence, our sample have all been retired for several years before our period of analysis. Thus, we address the likely effects of endogenous retirement that has been a focus of recent literature (Banks et al., 2010; Mazzonna and Peracchi 2012). In further robustness checks, we examine alternative treatments of the timing of retirement, and years since retirement. 


\section{Initial Results}

Table 2 provides initial estimates of (1) and provides the association between internet usage and the delayed recall test. In the first two columns, the sample includes both men and women. The estimates indicate that people who use the internet after they retired can recall 0.487 more words in the delayed recall test. ${ }^{9}$ To aid interpretation of the magnitude of this relationship, the second column presents a corresponding estimate where the dependent variable is instead the normalised number of words. The results show that internet usage is associated with an increase of around 0.233 of a standard deviation in the delayed recall test.

\section{INSERT TABLE 2}

Table 2 also reports selected coefficients of other covariates. In general, the signs of the coefficients fit with expectations. Current cognitive function is strongly related to cognitive function two years previous. Cognitive function declines with age but is positively correlated with education and income. There are substantial gender differences in cognitive function with males having 0.151 (approx. $1 / 3$ word) of a standard deviation lower cognitive function. This gender difference motivates us to estimate models separately for men and women. The middle and right panels of Table 2 display the estimated coefficients when we split the sample by gender. We can see in these panels that although the size of the internet usage coefficients is larger for women, the coefficients are broadly of the same magnitude.

As discussed above, non-random patterns of home computer ownership and internet usage present a challenge to the interpretation of these estimates. We use computer usage in pre-retirement jobs as a

\footnotetext{
${ }^{9}$ Appendix Table A3 shows that, without conditioning for other variables, internet usage is associated with a 0.723 of a standardized deviation increase in the delayed word recall test, approximately 1.3 more words recalled from a list of ten words. Adding cognitive function tested two years prior decreases the coefficient by over $50 \%$. Controlling for education further decreases the size of the coefficient. The inclusion of additional controls has little effect on estimates of our parameter of interest. In particular, health and household characteristics leave the main result essentially unaffected. This is worth noting as these variables might be viewed as bad controls. We highlight that, in practice, their inclusion does not change our main results. This remains true for all additional models.
} 
source of exogenous variation in the likelihood of internet usage post-retirement. Figure 2 shows the variation at industry-level in average computer usage in the participants' final jobs before retirement. Unsurprisingly, the computer manufacturing/retailing industry ranks the highest in average preretirement computer usage in the workplace with over $80 \%$ of those who used to work in computer manufacturing/retailing reporting that they used a computer, a percentage far higher than the overall average of $26 \% .{ }^{10}$ Other industries which had a high exposure to computers were financial services and research and development. Most manufacturing jobs are near the middle range of our ranking of computer usage. On the other hand, computers were rarely used in industries such as recycling and agriculture. Figure 3 provides similar information focusing on occupations rather than industries. Computer usage was widespread in professional and technical jobs, and managerial jobs. Beyond these jobs, there is lot of variation in pre-retirement exposure by occupation. This fits with a view of occupational spread of computerisation that was not simply a function of worker skill level. It is this variation in computerisation that provides us with variation conditional on prior cognitive function and education level. Figure 2 and Figure 3 also show that pre-retirement computer usage in work is a good predictor of post-retirement internet usage. In general, people who rarely used a computer in their final job have lower rates of post-retirement computer usage.

\section{INSERT FIGURE 2}

\section{INSERT FIGURE 3}

Table 3 presents the resultant instrumental variable estimates that correspond to equations $(2 \mathrm{a})$ and (2b). The bottom panel reports the first stage coefficient on having used a computer in the final, preretirement, job on current internet usage. This coefficient is of a large magnitude: using a computer in this job increases the likelihood of using the internet by 30 percentage points. This coefficient is statistically significant at the $1 \%$ level even conditional on a variety of individual characteristics relating

\footnotetext{
${ }^{10}$ When we re-estimated our main OLS and IV estimates excluding those working in the computer industry, our results were largely unaffected.
} 
to prior cognitive function, income, education, health and the household, and easily passes standard thresholds for weak instruments. ${ }^{11}$

\section{INSERT TABLE 3}

The top panel of Table 3 reports the IV estimates of the effect of internet usage on word recall, where again we report these estimates for the entire sample and for separate samples of men and women only. These estimates reveal positive effects that are roughly twice the size of the OLS estimates. These are large effects. For instance, the pooled estimates suggest that internet usage increases word recall by just under one word. These estimates reveal even more dramatic gender differences. Women who use the internet can recall 1.24 more words than similar women can; whereas men who use the internet can recall about 0.67 more words than similar men.

\section{Robustness}

\subsection{Alternative Outcomes, Covariates, Specifications, and Instruments}

We found that internet usage amongst retirees increases cognitive function, focusing on word recall. In this section, we explore a range of further estimates to assess the robustness of these findings across alternative outcomes, empirical specifications, and matters related to instrument choice.

First, while we have focused on delayed word recall, alternative measures of cognitive function are available in SHARE. In the 2013 wave of SHARE, immediate word recall is also available. This measure of cognitive function is similar to delayed word recall with the obvious difference that participants immediately list those words they remember after the list is read out. Estimates of the effect of internet usage on immediate word recall, estimated by OLS and IV, are reported in Panel A of Table 4. These results have a similar pattern to those in previous tables, although effect sizes are smaller. It is notable, however, that the IV estimates for men are small and not statistically different from zero. Second,

\footnotetext{
${ }^{11}$ A fuller set of first stage coefficients is shown in Appendix Table A4. Because the endogenous variable is binary, we also display the marginal effects from a logistic regression. The marginal effects from the logistic regression are very similar to the first stage 2SLS coefficients.
} 
a measure of numerical ability is available in the 2013 wave, along with past measures in 2011 and 2004. ${ }^{12}$ In practice, there is very little variation in numeracy score between 2011 and 2013, so instead we estimated a model including the 2004 numeracy scores as the lagged measure. The resultant estimates are shown in Panel B of Table 4. Again, these results largely conform to previous estimates, although the IV estimates from the men-only sample are sizeable but not statistically significant. Finally, there is a later measure (2015, Wave 6 of SHARE) of delayed word recall available for a smaller sample. ${ }^{13}$ Again, these estimates reveal positive and statistically significant effects of internet usage on cognitive function that are larger for the IV estimates. Together these estimates suggest our results are not driven by our choice of cognitive function measure, and that the effects of internet usage on cognitive function appear larger and more robust amongst women.

\section{INSERT TABLE 4}

Next, we examine the robustness of our results to a variety of alternative model specifications and control variables. In the upper panel of Table 5, we report estimates of two models that make different assumptions to the baseline value-added model. Alternative Model A removes the control for prior cognitive function. In comparison with our baseline value-added model, under Alternative Model A, the effect of internet usage is almost twice as large. This result suggests that the lagged dependent variable in the baseline model captures unobserved characteristics which affect both internet usage and cognitive scores. In Alternative Model B, we estimate the effect of internet usage on the change in test scores rather than on the level, conditional on initial test scores. Again, this specification leads to larger, more positive, estimates than our main specification. The lower panel of Table 5 demonstrates the robustness of our main estimates to a range of alternative controls, such as household assets, years since reaching their national statutory retirement age, measures of depression, and partner's age and education. All of these controls are potential confounding factors, although one must be careful when interpreting the

\footnotetext{
12 The measure of numeracy is based on a series of questions where respondents are presented with everyday situations where they have to calculate fractions and show awareness of compounding.

${ }^{13}$ In the main, we did not use the 2015 data for our analysis because the sample size in 2015 is $27 \%$ smaller than the sample size in 2013.
} 
resultant estimates as again these control variables themselves could be influenced by cognitive function and hence could be considered 'bad controls'. With this said, the estimates of interest are largely unaffected by the inclusion of these alternative controls. The only exception are models where we include both measures of depression and partner's education and age. In those models, while OLS estimates are unchanged, the IV estimates fall by roughly half and are only statistically significant at the $10 \%$ level.

\section{INSERT TABLE 5}

Next, we explore our IV strategy further. The intuition behind our instrument is that people choosing careers and occupations prior to the computerisation of workplaces from the 1980s onwards are subsequently exposed to different levels of computerisation because of factors related to ease of computerisation, task mix etc. Ideally, we would measure exposure to computers over an entire career but the data do not allow us to. Questions about usage of computers at work were only introduced in Wave 5 of SHARE which means that our main identification strategy utilises computer usage in the final job before retirement. While the intuition of our identifying assumption is clear, it is in practice not clear how best to operationalise our IV strategy. Here, we investigate the robustness of our IV results to alternative strategies. First, we adopt a strategy complementary to our original IV strategy that aims to capture duration of exposure to computers in the final job by interacting computer usage in the final job with years worked in this job. The resultant IV estimates are reported in Column 4 of Table 6. The estimates of the effect of internet usage on word recall are effectively unchanged by this strategy.

\section{INSERT TABLE 6}

An additional concern with our strategy is that while differences in computer usage between occupations might be random with respect to individuals' original job choices, individual variation in actual computer usage within occupation might be non-random. For instance, people might be sorted into workplaces, or into specific tasks within workplaces, based on their computer aptitude, and this aptitude could be related to later cognitive function. As an alternative strategy, we use average computer 
usage in the respondent's final occupation where the average values were generated from the SHARE data (excluding the ith individual). The results are reported in Column 5 of Table 6. This instrumental variable passes standard thresholds to detect weak instruments, and results in a larger estimate of the effect of internet usage on delayed word recall ( 0.762 of a standard deviation increase). Finally, the rate of computerisation of occupations is likely to have varied across countries. With this in mind, Column 6 provides further estimates where we use averages of computer usage in last job by occupation-country cells (again omitting the $i t h$ individual). The results are qualitatively unchanged.

\section{INSERT TABLE 6}

On a related point, a concern is that the task- and skill- mix of occupation might themselves influence the rate of cognitive decline. As a first step to investigating this, Table 7 reports estimates (OLS and IV) where we first include controls for whether the final job was in self-employment or as an employee in the public or private sector, followed by a range of controls for occupational skill level. Hence, the IV estimates are identified by within-occupation and within-employment type variation in computer usage in the respondent's final job. The main results are robust to these alternative strategies. For instance, the within-occupation estimates reveal that internet usage is leads to a 0.337 of a standard deviation increase in cognitive function. This estimate suggests that it is not occupational skills, and their correlation with computer usage, that is generating the increases in cognitive function.

\section{INSERT TABLE 7}

In the lower panel of Table 7, we further investigate the role of different skilled jobs in postretirement internet usage. Notably, the growth in workplace computerisation was concentrated in high skill occupations, but also in medium skill occupations where jobs consisted disproportionately of tasks that were routine in nature and hence more readily replicated by algorithm (Autor, Levy and Murnane 2003). We sorted occupations into four skill-level groups according to ISCO (International Labour Organisation, 1990) classification: elementary; medium-level; technicians and associate professionals; and professionals. The bottom panel of Table 7 reports OLS and IV estimates for these four occupational 
groups. Across all groups, OLS estimates reveal a positive relationship between internet usage and cognitive function, possibly largest amongst low skill workers. However, the IV effects are concentrated entirely amongst medium skill workers, even while the instrument passes standard tests of instrument weakness for technicians/associate professionals and professionals, respectively. These results fit with one interpretation of the local average treatment effect estimated by our IV strategy: People who otherwise might not have been exposed to computers are those who benefit from internet usage. Higher skilled workers, for instance, might have been more likely computer adopters in the absence of workplace exposure. It also raises two caveats regarding our results. Naturally, we cannot say anything causal about these always-takers, nor can we say anything about those not exposed to the instrument (e.g. low-skill workers). At the same time, one other aspect of the process of computerisation of routine jobs is the reduction of employment in medium skill jobs and movement into lower-skill jobs, although the extent of this varies by country (Goos et al, 2008).

As further robustness checks, we re-estimated our main models excluding specific groups who either might have substantially different patterns of computer usage and cognitive function and/or for whom our instrumental variable strategy is less likely to be applicable. First, we re-estimated our model excluding people who never worked. Clearly, these people cannot have been directly affected by computerisation patterns in the workforce, so they do not contribute to identifying the IV estimates. Second, we excluded people who retired early because they might have retired early due to negative health shocks which, in turn, might affect their post-retirement cognitive function and internet usage. Specifically, we drop all people who retired at least three years earlier than their national retirement age. Finally, we re-estimated our model excluding people who retired before 1980 because these people are less likely to have been affected by the large-scale computerization in workplaces from the 1980s on. In unreported estimates, excluding these people left both the OLS and IV estimates essentially unchanged.

\subsection{Heterogeneity and Mechanisms}


One issue is that our estimates might largely be caused by people from socio-economically advantaged backgrounds. For example, people with more schooling or greater ability are more likely to select skilled occupations that involve more computer usage, and their health outcomes, including cognitive function, are likely to be better irrespective of computer usage. To investigate this issue, we estimated our models separately across education qualifications using three combined categories of the International Standard Classification of Education (ISCED). These results are presented in Table 8. For the sake of precision, we estimate models pooled across genders. We can see from Table 8 that internet usage increases cognitive function across all three educational categories. There is some indication that these effects, while present, are smaller for people with secondary education as their highest qualification. However, some caution must be taken as these estimates, particularly the IV estimates, are quite imprecise and the confidence intervals overlap for all three educational categories.

\section{INSERT TABLE 8}

A second issue is the potential for age to affect attitudes towards technology. Younger cohorts might have more positive attitudes towards new technology, and they were more exposed to technological change in the workplace after the 1980s. In our data, $36 \%$ of people younger than 70 in 2013 reported using the internet; whereas, only $26 \%$ of people older than 75 reported using the internet. In unreported estimates, we find very little variation in either our OLS or IV estimates when we split our sample by age group (for instance 58-70 versus 70+). Likewise, we examined whether our results varied markedly by years since retirement. Again, there was little indication of variation by years since retirement. These results for age and retirement are additionally helpful in so for as our results were largely unchanged in younger $(<70)$ and shorter retirement period $(<15$ years $)$ groups where attrition due to death and incapacity will be less of a problem.

\section{INSERT TABLE 9}

Finally, while to this point we have found a robust positive effect of internet usage on cognitive function, this finding raises the question of what mechanisms are driving this positive effect. There are 
a range of potential mechanisms, but one point that must be highlighted is that this is not internet usage conditional on computer usage. As a result, and as highlighted earlier, it is not clear whether our results capture effects of computer usage more broadly, or specifically internet usage. SHARE does, however, contain a range of information on behaviours which we report in Table 9. These are presented as unconditional mean differences between internet users and non-users. These provide some indication of potential mechanisms. The categorical manner in which this data is reported makes comparisons sometimes difficult, but internet users read more frequently, and there is some indication that they are more likely to participate in clubs. There is little difference across puzzle games, card games and voluntary or charity work.

\section{Conclusion and Discussion}

Cognitive decline amongst older people is a leading indicator of a range of negative outcomes. This study examined the role of information technology, specifically internet usage, in influencing the cognitive function of people after retirement. In a large-scale multi-country setting, we estimate a value added model which demonstrates a positive association between internet usage and cognitive function. Furthermore, we adopt an instrumental variable strategy based on pre-retirement workplace exposure to computers to provide estimates of the effect of post-retirement IT usage on cognitive function. In this way, we go beyond existing correlational studies regarding how technology affects the well-being of older people.

We demonstrate that internet usage has substantial effects on the cognitive function of older people. Our IV estimates suggest that internet usage increases word recall by approximately 0.445 of a standard deviation. These results are larger for women, and are robust to a range of alternative measures of cognitive function, sample selection, functional form, and potential violations of our exclusion restriction. In practice, these effects could be generated by a range of mechanisms. Future research should focus on identifying the specific mechanisms through which IT usage influences the cognitive function of retirees. 


\section{References}

Angrist, J.D., \& J.S. Pischke. (2008). Mostly harmless econometrics: An empiricists companion . Princeton University Press.

Atalay, K., Barrett, G. F., \& Staneva, A. (2019). The effect of retirement on elderly cognitive functioning. Journal of Health Economics, 66:37-53.

Autor, D.H., L.F. Katz, \& A.B. Krueger. (1998). Computing Inequality: Have Computers Changed the Labor Market? The Quarterly Journal of Economics, 113(4): 1169-1213.

Autor, D.H., F. Levy, \& R.J. Murnane. (2003). The skill content of recent technological change: An empirical exploration. The Quarterly Journal of Economics, 118(4): 1279-1333.

Autor, D. H. (2015). Why Are There Still So Many Jobs? The History and Future of Workplace Automation. The Journal of Economic Perspectives, 29(3): 3-30.

Banks, J., C. O’Dea, \& Z. Oldfield. (2010). Cognitive function, numeracy and retirement saving trajectories. The Economic Journal, 120(548).

Bonsang, E., S. Adam, \& S. Perelman. (2012). Does retirement affect cognitive functioning? Journal of Health Economics, 31(3): 490-501.

Bresnahan, T.F. (1999). Computerisation and Wage Dispersion: An Analytical Reinterpretation. The Economic Journal, 109: F390-F415.

Celidoni, M., Dal Bianco, C., \& Weber, G. (2017). Retirement and cognitive decline. A longitudinal analysis using SHARE data. Journal of Health Economics, 56, 113-125.

Czaja, S.J., \& J. Sharit. (1993). Age differences in the performance of computer-based work. Psychology and Aging, 8(1): 59.

Czaja, S.J., J. Sharit, R. Ownby, D.L. Roth, \& S. Nair. (2001). Examining age differences in performance of a complex information search and retrieval task. Psychology and Aging, 16(4): 564.

De Luca, G., M. Celidoni, \& E. Trevisan (2015) Item nonresponse and imputation strategies in SHARE Wave 5. In Malter, F. and A. Börsch-Supan (Eds.) SHARE Wave 5: Innovations \& Methodology. Munich: MEA, Max Planck Institute for Social Law and Social Policy.

Elliot, A.J., C.J. Mooney, K.Z. Douthit, \& M.F. Lynch. (2013). Predictors of older adults' technology use and its relationship to depressive symptoms and well-being. Journals of Gerontology Series B: Psychological Sciences and Social Sciences, 69(5): 667-677.

Friedberg, L. (2003). The impact of technological change on older workers: Evidence from data on computer use. ILR Review, 56(3): 511-529.

Gatto, S.L., \& S.H. Tak. (2008). Computer, internet, and e-mail use among older adults: benefits and barriers. Educational Gerontology, 34(9): 800-811.

Goos, M., Manning, A., \& Salomons, A. (2009). Job polarization in Europe. American Economic Review, 99(2), 58-63. 
Heo, J., S. Chun, S. Lee, K. Lee, \& J. Kim. (2015). Internet use and well-being in older adults. Cyberpsychology, Behavior, and Social Networking, 18(5): 268-272.

Jones, B.D., \& U.J. Bayen. (1998). Teaching older adults to use computers: Recommendations based on cognitive aging research. Educational Gerontology: An International Quarterly, 24(7): 675-689.

Lee, B., Y. Chen, \& L. Hewitt. (2011). Age differences in constraints encountered by seniors in their use of computers and the internet. Computers in Human Behavior, 27(3): 1231-1237.

Lelkes, O. (2013). Happier and less isolated: Internet use in old age. Journal of Poverty and Social Justice, 21(1): 33-46.

Matthews, K., \& J. Nazroo. (2015). Understanding digital engagement in later life. University of Manchester. Retrieved May, 29, 2016.

Mazzonna, F., \& F. Peracchi. (2012). Ageing, cognitive abilities and retirement. European Economic Review, 56(4): 691-710.

McConatha, D., J.T. McConatha, \& R. Dermigny. (1994). The use of interactive computer services to enhance the quality of life for long-term care residents. The Gerontologist, 34(4): 553-556.

Rogers, W.A., A.J. Stronge, \& A.D. Fisk. (2005). Technology and aging. Reviews of Human Factors and Ergonomics, 1(1): 130-171.

Rohwedder, S., \& Willis, R. J. (2010). Mental retirement. Journal of Economic Perspectives, 24(1), 119-38.

Shapira, N., A. Barak, \& I. Gal. (2007) Promoting older adults' well-being through Internet training and use. Aging \& Mental Health, 11(5): 477-484.

Silver, M. P. (2014). Socio-economic status over the lifecourse and internet use in older adulthood. Ageing \& Society, 34(6): 1019-1034.

Slegers, K., M.P. Van Boxtel, \& J. Jolles. (2008). Effects of computer training and Internet usage on the well-being and quality of life of older adults: A randomized, controlled study. The Journals of Gerontology Series B: Psychological Sciences and Social Sciences, 63(3): P176-P184.

Slegers, K., M.P. Van Boxtel, \& J. Jolles. (2009). Effects of computer training and internet usage on cognitive abilities in older adults: a randomized controlled study. Aging Clinical and Experimental Research, 21(1): 43-54.

Slegers, K., M.P. Van Boxtel, \& J. Jolles. (2012). Computer use in older adults: determinants and the relationship with cognitive change over a 6 year episode. Computers in Human Behavior, 28(1): 1-10.

Tun, P.A., \& M.E. Lachman. (2010). The association between computer use and cognition across adulthood: use it so you wont lose it? Psychology and Aging, 25(3): 560.

White, H., E. McConnell, E. Clipp, L.G. Branch, R. Sloane, C. Pieper, \& T.L. Box. (2002). A randomized controlled trial of the psychosocial impact of providing internet training and access to older adults. Aging \& Mental Health, 6(3): 213-221. 
Zheng, R., J. Spears, M. Luptak, \& F. Wilby. (2015). Understanding older adults' perceptions of Internet use: An exploratory factor analysis. Educational Gerontology, 41(7): 504-518. 


\begin{tabular}{|c|c|c|c|c|c|c|}
\hline & Mean & Std. Dev. & Min. & Max. & $\begin{array}{l}\text { Mean of } \\
\text { Internet } \\
\text { Users } \\
\text { Minus } \\
\text { Mean of } \\
\text { Non-Users } \\
\end{array}$ & $\begin{array}{l}\text { P-value of } \\
\text { Difference by } \\
\text { Internet Usage }\end{array}$ \\
\hline \multicolumn{7}{|l|}{ Cognitive function: } \\
\hline Delayed word recall & 3.11 & 2.09 & 0 & 10 & 1.51 & $0.000 * * *$ \\
\hline Delayed word recall (2011) & 3.27 & 2.07 & 0 & 10 & 1.50 & $0.000 * * *$ \\
\hline \multicolumn{7}{|l|}{ Computer Usage: } \\
\hline Uses internet (post-retirement) & 0.27 & 0.45 & 0 & 1 & & \\
\hline Used computer in final job (pre-retirement) & 0.26 & 0.44 & 0 & 1 & 0.43 & $0.000 * * *$ \\
\hline \multicolumn{7}{|l|}{ Demographics and Life History: } \\
\hline Male & 0.45 & 0.50 & 0 & 1 & 0.18 & $0.000 * * *$ \\
\hline Age & 77.2 & 7.05 & 59 & 102 & -2.94 & $0.000 * * *$ \\
\hline Years of education & 9.74 & 4.46 & 0 & 25 & 3.64 & $0.000 * * *$ \\
\hline Never worked & 0.19 & 0.39 & 0 & 1 & -0.15 & $0.000 * * *$ \\
\hline Years retired & 17.68 & 7.54 & 0 & 56 & -3.02 & $0.000 * * *$ \\
\hline \multicolumn{7}{|l|}{ Household Characteristics: } \\
\hline Married or living with partner & 0.63 & 0.48 & 0 & 1 & 0.09 & $0.000 * * *$ \\
\hline Widow(er) & 0.26 & 0.44 & 0 & 1 & -0.11 & $0.000 * * *$ \\
\hline Household size & 1.8 & 0.73 & 1 & 7 & -0.04 & 0.107 \\
\hline Resides in large city & 0.10 & 0.30 & 0 & 1 & 0.01 & 0.279 \\
\hline Resides in rural area & 0.30 & 0.46 & 0 & 1 & -0.10 & $0.000 * * *$ \\
\hline Home owner & 0.72 & 0.45 & 0 & 1 & 0.03 & $0.084^{*}$ \\
\hline Living in nursing house & 0.003 & 0.06 & 0 & 1 & 0.004 & $0.001 * * *$ \\
\hline Total annual household income in Euro & 21384 & 28033 & 0 & 895719.1 & 7861.8 & $0.000 * * *$ \\
\hline \multicolumn{7}{|l|}{ Health: } \\
\hline Body mass index & 26.65 & 4.56 & 15 & 67 & -0.68 & $0.000 * * *$ \\
\hline Number of visits to doctor & 8.5 & 10.1 & 0 & 98 & -1.73 & $0.000 * * *$ \\
\hline Has long-term chronic disease & 0.86 & 0.34 & 0 & 1 & -0.06 & $0.000 * * *$ \\
\hline Physically inactive & 0.19 & 0.39 & 0 & 1 & -0.17 & $0.000 * * *$ \\
\hline Ever drank more than two glasses of wine daily & 0.10 & 0.30 & 0 & 1 & 0.07 & $0.000 * * *$ \\
\hline Ever smoked every day & 0.42 & 0.49 & 0 & 1 & 0.15 & $0.000 * * *$ \\
\hline
\end{tabular}


Table 2: OLS Estimates of the Effect of Internet Usage on Cognitive Test Score

$Y_{t}:$ Delayed Recall Test Score (2013)

\begin{tabular}{|c|c|c|c|c|c|c|}
\hline & \multicolumn{2}{|c|}{ All Observations } & \multicolumn{2}{|r|}{ Men Only } & \multicolumn{2}{|c|}{ Women Only } \\
\hline & $Y_{t}$ & Standardized $Y_{t}$ & $Y_{t}$ & Standardized $Y_{t}$ & $Y_{t}$ & Standardized $Y_{t}$ \\
\hline Uses internet $(D=1)$ & $\begin{array}{c}0.487 * * * \\
(0.071)\end{array}$ & $\begin{array}{c}0.233 * * * \\
(0.034)\end{array}$ & $\begin{array}{c}0.430 * * * \\
(0.098)\end{array}$ & $\begin{array}{c}0.205 * * * \\
(0.047)\end{array}$ & $\begin{array}{c}0.557 * * * \\
(0.103)\end{array}$ & $\begin{array}{c}0.266 * * * \\
(0.049)\end{array}$ \\
\hline$Y_{t-1}(2011)$ & $\begin{array}{c}0.456^{* * *} \\
(0.016)\end{array}$ & $\begin{array}{c}0.451 * * * \\
(0.016)\end{array}$ & $\begin{array}{c}0.400^{* * *} \\
(0.024)\end{array}$ & $\begin{array}{c}0.396 * * * \\
(0.024)\end{array}$ & $\begin{array}{c}0.495 * * * \\
(0.021)\end{array}$ & $\begin{array}{c}0.49^{* * *} \\
(0.021)\end{array}$ \\
\hline Age & $\begin{array}{l}-0.064 \\
(0.064)\end{array}$ & $\begin{array}{l}-0.031 \\
(0.030)\end{array}$ & $\begin{array}{l}-0.127 \\
(0.101)\end{array}$ & $\begin{array}{l}-0.061 \\
(0.048)\end{array}$ & $\begin{array}{c}-0.034 \\
(0.083)\end{array}$ & $\begin{array}{l}-0.016 \\
(0.040)\end{array}$ \\
\hline $\mathrm{Age}^{2} / 100$ & $\begin{array}{c}0.024 \\
(0.041)\end{array}$ & $\begin{array}{c}0.011 \\
(0.019)\end{array}$ & $\begin{array}{c}0.067 \\
(0.064)\end{array}$ & $\begin{array}{c}0.032 \\
(0.031)\end{array}$ & $\begin{array}{l}-0.003 \\
(0.054)\end{array}$ & $\begin{array}{l}-0.001 \\
(0.026)\end{array}$ \\
\hline Men & $\begin{array}{c}-0.317 * * * \\
(0.068)\end{array}$ & $\begin{array}{c}-0.151^{* * * *} \\
(0.032)\end{array}$ & & & & \\
\hline Years of education & $\begin{array}{c}0.048^{* * *} \\
(0.008)\end{array}$ & $\begin{array}{c}0.023 * * * \\
(0.004)\end{array}$ & $\begin{array}{c}0.054 * * * \\
(0.011)\end{array}$ & $\begin{array}{c}0.026 * * * \\
(0.005)\end{array}$ & $\begin{array}{c}0.040 * * * \\
(0.012)\end{array}$ & $\begin{array}{c}0.019 * * * \\
(0.006)\end{array}$ \\
\hline Income (top $25 \%$ ) & $\begin{array}{c}0.251 * * \\
(0.120)\end{array}$ & $\begin{array}{c}0.120 * * \\
(0.057)\end{array}$ & $\begin{array}{l}0.320^{*} \\
(0.188)\end{array}$ & $\begin{array}{l}0.153^{*} \\
(0.090)\end{array}$ & $\begin{array}{c}0.213 \\
(0.155)\end{array}$ & $\begin{array}{c}0.102 \\
(0.074)\end{array}$ \\
\hline $\begin{array}{l}R \text {-squared } \\
n\end{array}$ & & $\begin{array}{c}0.390 \\
3798\end{array}$ & & $\begin{array}{c}0.344 \\
1717\end{array}$ & & $\begin{array}{l}0.441 \\
2081\end{array}$ \\
\hline
\end{tabular}

Notes: * significant at $10 \%$ level; ** significant at $5 \%$ level; ***significant at $1 \%$ level.

Robust standard errors clustered at household level in parentheses. There are 3199 clusters for all observations, 1717 for men only, 2076 for women only.

Regressions also control for years retired, health status, household characteristics, and country fixed effects. For those who never worked, years retired were replaced with years since reaching national statutory retirement age. Health status comprised standardized body mass index, standardized number of doctor visits, whether has long-term chronic disease, whether physically inactive, whether drinks (more than two glasses) every day, and whether smokes every day. Household characteristics comprised marital status, household size, living in city, town or countryside, home ownership, whether living in nursing house, and quartiles of total household income (transformed using PPP index). 
Table 3: IV Estimates of the Effect of Internet Usage on Cognitive Test Score

\begin{tabular}{|c|c|c|c|}
\hline $\begin{array}{r}\mathrm{Y}_{\mathrm{t}}: \text { Delayed Recall Test } \\
\text { Score (2013) }\end{array}$ & & & \\
\hline Uses internet $(D=1)$ & $\begin{array}{c}\text { All } \\
0.932 * * * \\
{[0.445]} \\
(0.240)\end{array}$ & $\begin{array}{l}\text { Male } \\
0.669 * \\
{[0.320]} \\
(0.344)\end{array}$ & $\begin{array}{c}\text { Female } \\
1.238 * * * \\
{[0.591]} \\
(0.370)\end{array}$ \\
\hline$Y_{t-1}(2011)$ & $\begin{array}{c}0.442 * * * \\
(0.017)\end{array}$ & $\begin{array}{c}0.391 * * * \\
(0.028)\end{array}$ & $\begin{array}{r}0.476^{* * *} \\
(0.023)\end{array}$ \\
\hline Age & $\begin{array}{l}-0.062 \\
(0.063)\end{array}$ & $\begin{array}{l}-0.113 \\
(0.101)\end{array}$ & $\begin{array}{l}-0.041 \\
(0.083)\end{array}$ \\
\hline $\mathrm{Age}^{2} / 100$ & $\begin{array}{c}0.025 \\
(0.041)\end{array}$ & $\begin{array}{l}0.060 \\
(0.064)\end{array}$ & $\begin{array}{c}0.005 \\
(0.054)\end{array}$ \\
\hline Men & $\begin{array}{c}-0.370^{* * *} \\
(0.073)\end{array}$ & & \\
\hline Years of education & $\begin{array}{c}0.040 * * * \\
(0.009)\end{array}$ & $\begin{array}{c}0.049 * * * \\
(0.012)\end{array}$ & $\begin{array}{r}0.032 * * * \\
(0.012)\end{array}$ \\
\hline Income (top 25\%) & $\begin{array}{l}0.204^{*} \\
(0.123)\end{array}$ & $\begin{array}{c}0.292 \\
(0.189)\end{array}$ & $\begin{array}{c}0.155 \\
(0.162)\end{array}$ \\
\hline $\begin{array}{l}\text { IV first-stage coefficient } \\
\text { Computer in final job } \\
\text { before retirement }\end{array}$ & $\begin{array}{c}0.305^{* * *} \\
(0.020)\end{array}$ & $\begin{array}{c}0.290^{* * *} \\
(0.028)\end{array}$ & $\begin{array}{c}0.302 * * * \\
(0.031)\end{array}$ \\
\hline $\begin{array}{l}\text { Kleibergen-Paap F statistic } \\
\text { Partial R-squared } \\
R \text {-squared } \\
N\end{array}$ & $\begin{array}{c}227.51 \\
0.085 \\
0.383 \\
3798\end{array}$ & $\begin{array}{c}104.63 \\
0.081 \\
0.342 \\
1717\end{array}$ & $\begin{array}{l}95.63 \\
0.075 \\
0.429 \\
2081\end{array}$ \\
\hline
\end{tabular}

Notes: * significant at $10 \%$ level; ** significant at $5 \%$ level; ***significant at $1 \%$ level.

Estimates where outcome is standardized measure of cognition are shown in square brackets.

Robust standard errors clustered at household level are in parentheses. There are 3199 clusters for the All Observations, 1717 for Men, 2076 for Women.

Controls are as per Table 2. 
Table 4: The Effect of Internet usage on Other Measures of Cognitive Function

\begin{tabular}{|c|c|c|c|c|c|c|}
\hline \multirow[t]{3}{*}{ Panel A } & \multicolumn{6}{|c|}{ Immediate Word Recall (2013) } \\
\hline & \multicolumn{2}{|c|}{ All Observations } & \multicolumn{2}{|c|}{ Men Only } & \multicolumn{2}{|c|}{ Women Only } \\
\hline & OLS & IV & $O L S$ & IV & OLS & IV \\
\hline Uses internet $(D=1)$ & $\begin{array}{c}0.199 * * * \\
(0.034)\end{array}$ & $\begin{array}{c}0.303 * * * \\
(0.117)\end{array}$ & $\begin{array}{c}0.135 * * * \\
(0.047)\end{array}$ & $\begin{array}{c}0.030 \\
(0.165)\end{array}$ & $\begin{array}{c}0.259 * * * \\
(0.048)\end{array}$ & $\begin{array}{c}0.606 * * * \\
(0.187)\end{array}$ \\
\hline$N$ & \multicolumn{2}{|c|}{3798} & \multicolumn{2}{|c|}{1717} & \multicolumn{2}{|c|}{2081} \\
\hline Kleibergen-Paap F statistic & \multicolumn{2}{|r|}{237.33} & \multicolumn{2}{|r|}{110.18} & \multicolumn{2}{|r|}{100.81} \\
\hline \multirow[t]{3}{*}{ Panel B } & \multicolumn{6}{|c|}{ Numeracy (2013) } \\
\hline & \multicolumn{2}{|c|}{ All Observations } & \multicolumn{2}{|c|}{ Men Only } & \multicolumn{2}{|c|}{ Women Only } \\
\hline & $O L S$ & IV & $O L S$ & IV & OLS & IV \\
\hline Uses internet $(D=1)$ & $\begin{array}{c}0.184 * * * \\
(0.034)\end{array}$ & $\begin{array}{c}0.316 * * * \\
(0.116)\end{array}$ & $\begin{array}{c}0.010 * * \\
(0.046)\end{array}$ & $\begin{array}{c}0.252 \\
(0.160)\end{array}$ & $\begin{array}{c}0.279 * * * \\
(0.051)\end{array}$ & $\begin{array}{c}0.460 * * \\
(0.193)\end{array}$ \\
\hline$N$ & \multicolumn{2}{|c|}{3792} & \multicolumn{2}{|c|}{1714} & \multicolumn{2}{|c|}{2078} \\
\hline Kleibergen-Paap F statistic & \multicolumn{2}{|c|}{233.97} & \multicolumn{2}{|r|}{110.89} & \multicolumn{2}{|r|}{96.96} \\
\hline \multirow[t]{3}{*}{ Panel C } & \multicolumn{6}{|c|}{ Delayed Word Recall (2015) } \\
\hline & \multicolumn{2}{|c|}{ All Observations } & \multicolumn{2}{|c|}{ Men Only } & \multicolumn{2}{|c|}{ Women Only } \\
\hline & $O L S$ & IV & $O L S$ & IV & $O L S$ & IV \\
\hline Uses internet $(D=1)$ & $\begin{array}{c}0.217 * * * \\
(0.041)\end{array}$ & $\begin{array}{c}0.392 * * * \\
(0.146)\end{array}$ & $\begin{array}{l}0.110 * \\
(0.057)\end{array}$ & $\begin{array}{l}0.355^{*} \\
(0.189)\end{array}$ & $\begin{array}{c}0.344 * * * \\
(0.059)\end{array}$ & $\begin{array}{c}0.526 * * \\
(0.247)\end{array}$ \\
\hline$N$ & \multicolumn{2}{|c|}{2783} & \multicolumn{2}{|c|}{1227} & \multicolumn{2}{|c|}{1556} \\
\hline Kleibergen-Paap F statistic & & 154.45 & & 78.69 & & 56.91 \\
\hline
\end{tabular}

Notes: * significant at $10 \%$ level; ** significant at $5 \%$ level; ***significant at $1 \%$ level.

Robust standard errors clustered at household level are in parentheses.

All controls are as per Table 2.

The raw scores of the numeracy test (ranges from 0-5) were used. The lagged values of numeracy were from 2004 because of the trivial changes in numeracy scores between the 2011 and 2013. Word recall scores were standardized. 
Table 5: Specification Checks to Models and Alternative Controls:

$Y_{t}:$ Delayed Recall Test Score (2013)

Upper Panel:

Alternative Specifications

\begin{tabular}{|c|c|c|c|}
\hline \multicolumn{2}{|c|}{$\begin{array}{c}\text { Standardized } Y_{t} \\
\text { Alternative Model A }\end{array}$} & \multicolumn{2}{|c|}{$\begin{array}{c}Y_{t}-Y_{t-1} \\
\text { Alternative Model B }\end{array}$} \\
\hline OLS & IV & OLS & IV \\
\hline $\begin{array}{c}0.394 * * * \\
(0.038)\end{array}$ & $\begin{array}{c}0.856 * * * \\
(0.125)\end{array}$ & $\begin{array}{c}0.487 * * * \\
(0.071) \\
\checkmark\end{array}$ & $\begin{array}{c}0.932 * * * \\
(0.240) \\
\checkmark\end{array}$ \\
\hline 0.240 & 0.209 & 0.267 & 0.259 \\
\hline & 254.45 & & 227.51 \\
\hline
\end{tabular}

\section{Uses internet $(D=1)$}

$Y_{t-1}(2011)$

$R$-squared

$N$

Kleibergen-Paap F statistic

Lower Panel:

Alternative Controls

\section{Uses internet $(D=1)$}

\begin{tabular}{cccccccc} 
OLS & IV & OLS & IV & OLS & IV & OLS & IV \\
\hline $0.233 * * *$ & $\mathbf{0 . 4 4 1 * * *}$ & $\mathbf{0 . 2 3 2} * * *$ & $\mathbf{0 . 4 3 3} * * *$ & $\mathbf{0 . 2 2 5} * * *$ & $\mathbf{0 . 4 2 8} * * *$ & $\mathbf{0 . 2 2 3 * * *}$ & $\mathbf{0 . 2 3 2} *$ \\
$(\mathbf{0 . 0 3 4 )}$ & $(\mathbf{0 . 1 1 1 )}$ & $(\mathbf{0 . 0 3 4 )}$ & $\mathbf{( 0 . 1 1 5 )}$ & $\mathbf{( 0 . 0 3 4 )}$ & $\mathbf{( 0 . 1 1 6 )}$ & $\mathbf{( 0 . 0 4 1 )}$ & $\mathbf{( 0 . 1 3 9 )}$
\end{tabular}

\section{Alternative Controls}

Household Asset

Years Since Statutory Retirement Age

Depression Score

Partner's Age and Education

$R$-squared

$N$

0.389

$\checkmark$

Kleibergen-Paap F statistic

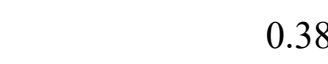

Notes: * significant at $10 \%$ lever

Robust standard errors clustered at household level are shown in parentheses.

The Upper Panel shows other specifications. The Lower Panel shows alternative controls such as retirement year, household net worth, depression scores (Eurod) in the year 2004, and partner's information 


\section{Uses internet $(D=1)$}

\section{Excluded Instruments}

Used computer in final job before retirement

Years worked in final job before retirement

Used computer * Years worked

ISCO computer usage mean in final job

ISCO-country computer usage mean in final job

\section{$R$-squared}

$n$

Number of excluded instruments

Partial R-squared

Kleibergen-Paap F statistic

Over-identification test

\begin{tabular}{cccccc}
$(1)$ & $(2)$ & $(3)$ & $(4)$ & $(5)$ & $(6)$ \\
OLS & IV & IV & IV & IV & IV \\
\hline $\mathbf{0 . 2 3 3} * * *$ & $\mathbf{0 . 4 4 5} * * *$ & $\mathbf{0 . 4 4 3 * * *}$ & $\mathbf{0 . 4 6 2} * * *$ & $\mathbf{0 . 7 7 8 * * *}$ & $\mathbf{0 . 4 5 1 * * *}$ \\
$\mathbf{( 0 . 0 3 4 )}$ & $\mathbf{( 0 . 1 1 5 )}$ & $\mathbf{( 0 . 1 1 5 )}$ & $\mathbf{( 0 . 1 1 3 )}$ & $\mathbf{( 0 . 1 5 5 )}$ & $\mathbf{( 0 . 1 4 9 )}$
\end{tabular}

Notes:

* significant at $10 \%$ level; ** significant at $5 \%$ level; *** significant at $1 \%$ level.

Robust standard errors are clustered at household level and are shown in parentheses.

All controls are as per Table 2 .

Over-identification test is the Hansen J statistic with a null hypothesis that the instruments are uncorrelated with the error term, and that the excluded instruments are correctly excluded from the estimated equation. Endogeneity test is under the null hypothesis that the specified endogenous regressors can actually be treated as exogenous. All these tests are heteroskedasticity robust. The test statistic is reported.

In SHARE, the original four-digit occupation code (ISCO-88) has more than 500 categories. We use 44 two-digit ISCO code. For the people who never worked, the variables of computer usage in the final job before retirement, and ISCO codes are replaced with zero. All control variables are the same as the main OLS specifications. 
Table 7: OLS and IV Estimates and Occupation

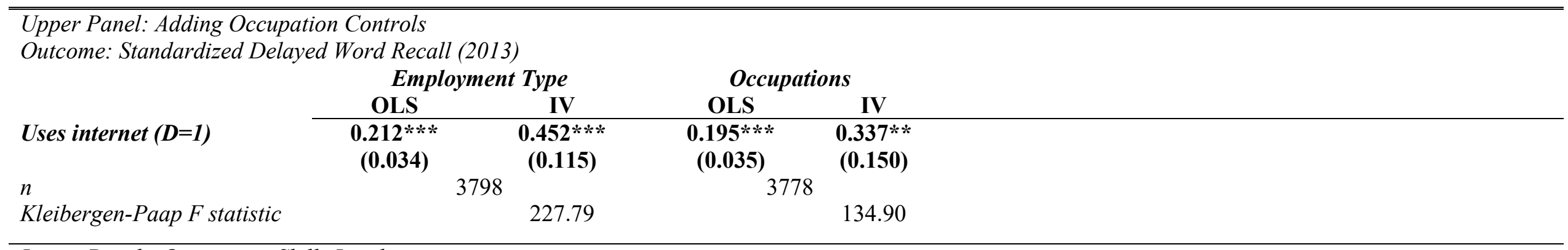

Lower Panel: Occupation Skills Level

Outcome: Standardized Delayed Word Recall (2013)

\begin{tabular}{|c|c|c|c|c|c|c|c|c|}
\hline \multirow[b]{3}{*}{ Uses internet $(D=1)$} & \multicolumn{2}{|c|}{ Elementary } & \multicolumn{2}{|c|}{ Medium } & \multicolumn{2}{|c|}{$\begin{array}{l}\text { Technicians \& } \\
\text { Associate Profs }\end{array}$} & \multicolumn{2}{|c|}{ Professionals } \\
\hline & OLS & IV & OLS & IV & OLS & IV & OLS & IV \\
\hline & $\begin{array}{c}0.318 * * \\
(0.139)\end{array}$ & $\begin{array}{l}-1.262 \\
(1.503)\end{array}$ & $\begin{array}{c}\mathbf{0 . 1 5 9} * * * \\
(\mathbf{0 . 0 5 6 )}\end{array}$ & $\begin{array}{c}0.772 * * * \\
(0.211)\end{array}$ & $\begin{array}{l}0.215^{* * *} \\
(0.088)\end{array}$ & $\begin{array}{l}-0.288 \\
(0.363)\end{array}$ & $\begin{array}{l}0.166 * \\
(0.091)\end{array}$ & $\begin{array}{c}0.039 \\
(\mathbf{0 . 3 0 1})\end{array}$ \\
\hline Mean: Delayed word recall & \multirow{2}{*}{\multicolumn{2}{|c|}{2.31}} & \multirow{2}{*}{\multicolumn{2}{|c|}{2.96}} & \multirow{2}{*}{\multicolumn{2}{|c|}{3.79}} & \multirow{2}{*}{\multicolumn{2}{|c|}{4.19}} \\
\hline (2013) & & & & & & & & \\
\hline Mean: Uses internet & \multicolumn{2}{|c|}{0.09} & \multicolumn{2}{|c|}{0.21} & \multicolumn{2}{|c|}{0.45} & \multicolumn{2}{|c|}{0.55} \\
\hline $\begin{array}{l}\text { Mean: Used computer in } \\
\text { final job }\end{array}$ & \multicolumn{2}{|c|}{0.05} & \multicolumn{2}{|c|}{0.19} & \multicolumn{2}{|c|}{0.45} & \multicolumn{2}{|c|}{0.43} \\
\hline$n$ & \multicolumn{2}{|c|}{338} & \multicolumn{2}{|c|}{1457} & \multicolumn{2}{|c|}{437} & \multicolumn{2}{|c|}{426} \\
\hline Kleibergen-Paap F statistic & & 2.17 & & 75.61 & & 20.21 & & 34.52 \\
\hline
\end{tabular}

Notes: * significant at $10 \%$ level; ** significant at $5 \%$ level; ***significant at $1 \%$ level.

Robust standard errors are clustered at household level are shown in parentheses.

All controls are as per Table 2.

Employment Type has four categories: employed (public sector, non-civil servant), employed (public sector, civil servant), employed (private sector), and self-employed. Occupation skills level is defined by the International Labour Organization (ILO). "Elementary" group covers occupations whose main tasks is selling goods in the street, doorkeeping, cleaning, or labouring in agriculture, fishing, mining, construction and manufacturing. "Technician and Associate Professionals" group includes occupations whose main tasks require technical knowledge and experience in one or more fields of physical and life sciences, or social sciences. "Medium" group includes clerks, service workers, shop sales assistants, skilled agricultural and fishery workers, craft and related trade workers, plant and machine operators and assemblers. "Professionals" group includes occupations whose main task require a high level of professional knowledge and experience. 
Table 8: OLS and IV Estimates by Education

\begin{tabular}{|c|c|c|c|c|c|c|}
\hline \multicolumn{7}{|c|}{ Outcome: Standardized Delayed Word Recall } \\
\hline & \multicolumn{2}{|c|}{ Pre-primary \& Primary } & \multicolumn{2}{|c|}{$\begin{array}{c}\text { ISCED Categories } \\
\text { Secondary }\end{array}$} & \multicolumn{2}{|c|}{ Bachelor \& Above } \\
\hline & OLS & IV & OLS & IV & OLS & IV \\
\hline Uses internet $(D=1)$ & $\begin{array}{c}0.237 * * * \\
(0.071)\end{array}$ & $\begin{array}{r}0.545^{* * *} \\
(0.267)\end{array}$ & $\begin{array}{c}0.192 * * * \\
(0.047)\end{array}$ & $\begin{array}{r}0.337^{* * *} \\
(0.172)\end{array}$ & $\begin{array}{c}0.230 * * * \\
(0.073)\end{array}$ & $\begin{aligned} 0.518^{*} \\
(0.305)\end{aligned}$ \\
\hline Mean: Delayed word recall (2013) & 2.3 & & & & & \\
\hline Mean: Uses internet & 0.1 & & & & & \\
\hline Mean: Used computer in final job & $0 .($ & & & & & \\
\hline$n$ & 15 & & & & & \\
\hline Kleibergen-Paap F statistic & & 34.14 & & 91.96 & & 31.76 \\
\hline
\end{tabular}

Notes: * significant at $10 \%$ level; ** significant at $5 \%$ level; ***significant at $1 \%$ level.

Robust standard errors are clustered at household level are shown in parentheses.

All controls are as per Table 2. 
Table 9: Activities and Internet Usage

\begin{tabular}{|c|c|c|c|c|}
\hline Activities & Mean & $\begin{array}{c}\text { Mean } \\
\text { (Internet User) }\end{array}$ & $\begin{array}{c}\text { Mean } \\
\text { (Inactive } \\
\text { Internet User) }\end{array}$ & $\begin{array}{c}\text { p-value of } \\
\text { Difference by } \\
\text { Internet Usage }\end{array}$ \\
\hline \multicolumn{5}{|l|}{ Reading } \\
\hline Almost everyday & 0.61 & 0.83 & 0.52 & $0.000 * * *$ \\
\hline Almost every week & 0.08 & 0.06 & 0.09 & $0.000 * * *$ \\
\hline Less often & 0.01 & 0.004 & 0.01 & $0.02 * *$ \\
\hline Never & 0.29 & 0.11 & 0.36 & $0.000 * * *$ \\
\hline \multicolumn{5}{|l|}{ Puzzle Games } \\
\hline Almost everyday & 0.28 & 0.43 & 0.23 & $0.000 * * *$ \\
\hline Almost every week & 0.11 & 0.15 & 0.09 & $0.000 * * *$ \\
\hline Less often & 0.01 & 0.02 & 0.01 & 0.274 \\
\hline Never & 0.58 & 0.38 & 0.65 & $0.000 * * *$ \\
\hline \multicolumn{5}{|l|}{ Card Games } \\
\hline Almost everyday & 0.07 & 0.09 & 0.06 & $0.000 * * *$ \\
\hline Almost every week & 0.13 & 0.18 & 0.11 & $0.000 * * *$ \\
\hline Less often & 0.04 & 0.05 & 0.04 & $0.03 * *$ \\
\hline Never & 0.70 & 0.58 & 0.75 & $0.000 * * *$ \\
\hline \multicolumn{5}{|c|}{ Clubs (Sports, social etc.) } \\
\hline Almost everyday & 0.03 & 0.07 & 0.02 & $0.000 * * *$ \\
\hline Almost every week & 0.16 & 0.27 & 0.11 & $0.000 * * *$ \\
\hline Less often & 0.02 & 0.03 & 0.02 & $0.01 * *$ \\
\hline Never & 0.73 & 0.54 & 0.80 & $0.000 * * *$ \\
\hline \multicolumn{5}{|c|}{ Voluntary or Charity work } \\
\hline Almost everyday & 0.03 & 0.07 & 0.02 & $0.000 * * *$ \\
\hline Almost every week & 0.09 & 0.16 & 0.06 & $0.000 * * *$ \\
\hline Less often & 0.03 & 0.04 & 0.02 & $0.01 * * *$ \\
\hline Never & 0.81 & 0.66 & 0.87 & $0.000 * * *$ \\
\hline
\end{tabular}

Notes: $\mathrm{n}=3758$

* significant at $10 \%$ level; ** significant at $5 \%$ level; ***significant at $1 \%$ level.

The "inactive Internet users" refer to the people who report no recent internet use during previous seven days. The last column presents the p-values of difference by current internet usage. The activities reported here are taken from wave 5 (2013). 


\section{Wave Participation}

\section{Interviewed}

$$
\text { Age }>=50
$$

26942

12427

27984

9902
Retired

12547

6960

6057
Retired Since 2004

12547

4378

3164
Never Worked

Total

Waves 1, 4 \& 5 (to 2013)

Notes: * significant at $10 \%$ level; ** significant at $5 \%$ level; ***significant at $1 \%$ level.

Our sample comprises this who have been retired since 2004. Because of missing variables, we have a sample of 3798 in the main analysis.

In the lower panel, the comparison group is the people who are aged over 50 and also participated in all Waves 1,4 and 5 but who were still working or doing other temporary paid jobs in Wave 5. The last column in the lower panel reports the difference of the mean measures across two samples. For those who never worked, years retired were replaced with years since reaching national statutory retirement age.

†household income is imputed using the fully conditional specification method and was obtained by aggregating individual income components at the household level. For more details, see De Luca et al. (2015). 
Table A2: Summary Statistics by Country

\begin{tabular}{lccccccc}
\hline \multicolumn{1}{c}{ Country } & $\boldsymbol{n}$ & $\begin{array}{c}\text { Delayed Word } \\
\text { Recall }\end{array}$ & $\begin{array}{c}\text { Uses } \\
\text { Internet } \\
\text { (Mean) }\end{array}$ & $\begin{array}{c}\text { Used computer } \\
\text { in Final Job } \\
\text { (Mean) }\end{array}$ & $\begin{array}{c}\text { Statutory } \\
\text { Retirement } \\
\text { Age Men }\end{array}$ & $\begin{array}{c}\text { Statutory } \\
\text { Retirement } \\
\text { Age Women }\end{array}$ & $\begin{array}{c}\text { Never } \\
\text { Worked }\end{array}$ \\
\hline Austria & 269 & 3.74 & 0.22 & 0.25 & 65 & 60 & $11.8 \%$ \\
Germany & 247 & 3.56 & 0.30 & 0.26 & 65 & 60 & $4.9 \%$ \\
Sweden & 356 & 3.30 & 0.38 & 0.45 & 67 & 67 & $0.5 \%$ \\
Netherlands & 272 & 3.32 & 0.47 & 0.30 & 65 & 65 & $19.9 \%$ \\
Spain & 465 & 2.04 & 0.62 & 0.03 & 65 & 65 & $50.1 \%$ \\
Italy & 622 & 2.59 & 0.09 & 0.09 & 60 & 55 & $28.5 \%$ \\
France & 507 & 3.31 & 0.33 & 0.27 & 65 & 65 & $8.7 \%$ \\
Denmark & 250 & 3.68 & 0.49 & 0.30 & 67 & 67 & $1.2 \%$ \\
Switzerland & 122 & 3.38 & 0.32 & 0.30 & 65 & 63 & $9.8 \%$ \\
Belgium & 688 & 3.34 & 0.33 & 0.22 & 65 & 60 & $20.9 \%$ \\
\hline \hline
\end{tabular}

\section{Notes:}

$†$ Past computer usage in the final job before retirement excludes the people who never worked.

National statutory retirement age as per the Wave 3 of SHARE. 


\begin{tabular}{|c|c|c|c|c|c|c|c|c|c|c|c|}
\hline & (1) & $(2)$ & (3) & (4) & (5) & (6) & (7) & $(8)$ & (9) & $(10)$ & (11) \\
\hline Uses internet $(D=1)$ & $\begin{array}{c}0.723 * * * \\
(0.034)\end{array}$ & $\begin{array}{c}0.339 * * * \\
(0.031)\end{array}$ & $\begin{array}{c}0.316^{* * * *} \\
(0.031)\end{array}$ & $\begin{array}{c}0.315^{* * * *} \\
(0.031)\end{array}$ & $\begin{array}{c}\mathbf{0 . 3 3 1} * * * \\
(0.032)\end{array}$ & $\begin{array}{c}0.255^{* * * *} \\
(0.033)\end{array}$ & $\begin{array}{c}0.256 * * * * \\
(0.033)\end{array}$ & $\begin{array}{c}0.251 * * * \\
(0.033)\end{array}$ & $\begin{array}{c}0.240 * * * * \\
(0.033)\end{array}$ & $\begin{array}{c}0.235^{* * *} \\
(\mathbf{0 . 0 3 3})\end{array}$ & $\begin{array}{c}0.233 * * * \\
(\mathbf{0 . 0 3 4})\end{array}$ \\
\hline$Y_{t-1}(2011)$ & & $\begin{array}{c}0.530 * * * \\
(0.014)\end{array}$ & $\begin{array}{c}0.510 * * * \\
(0.015)\end{array}$ & $\begin{array}{c}0.510 * * * \\
(0.015)\end{array}$ & $\begin{array}{c}0.506^{* * *} \\
(0.015)\end{array}$ & $\begin{array}{c}0.476 * * * \\
(0.015)\end{array}$ & $\begin{array}{c}0.476^{* * * *} \\
(0.015)\end{array}$ & $\begin{array}{c}0.468 * * * \\
(0.015)\end{array}$ & $\begin{array}{c}0.460 * * * \\
(0.016)\end{array}$ & $\begin{array}{c}0.458 * * * \\
(0.016)\end{array}$ & $\begin{array}{c}0.451^{* * *} \\
(0.016)\end{array}$ \\
\hline Age & & & $\begin{array}{c}-0.013 * * * \\
(0.002)\end{array}$ & $\begin{array}{c}0.003 \\
(0.029)\end{array}$ & $\begin{array}{c}0.011 \\
(0.030)\end{array}$ & $\begin{array}{c}0.004 \\
(0.029)\end{array}$ & $\begin{array}{c}0.003 \\
(0.029)\end{array}$ & $\begin{array}{l}-0.022 \\
(0.030)\end{array}$ & $\begin{array}{l}-0.032 \\
(0.030)\end{array}$ & $\begin{array}{l}-0.034 \\
(0.030)\end{array}$ & $\begin{array}{l}-0.031 \\
(0.030)\end{array}$ \\
\hline $\mathrm{Age}^{2} / 100$ & & & & $\begin{array}{l}-0.010 \\
(0.019)\end{array}$ & $\begin{array}{l}-0.015 \\
(0.019)\end{array}$ & $\begin{array}{l}-0.011 \\
(0.019)\end{array}$ & $\begin{array}{l}-0.010 \\
(0.019)\end{array}$ & $\begin{array}{c}0.005 \\
(0.019)\end{array}$ & $\begin{array}{c}0.012 \\
(0.019)\end{array}$ & $\begin{array}{c}0.013 \\
(0.020)\end{array}$ & $\begin{array}{c}0.011 \\
(0.019)\end{array}$ \\
\hline Men & & & & & $\begin{array}{c}-0.069 * * * \\
(0.026)\end{array}$ & $\begin{array}{c}-0.087 * * * \\
(0.026)\end{array}$ & $\begin{array}{c}-0.097 * * * \\
(0.026)\end{array}$ & $\begin{array}{c}-0.141^{* * *} \\
(0.029)\end{array}$ & $\begin{array}{c}-0.164 * * * \\
(0.031)\end{array}$ & $\begin{array}{c}-0.156^{* * * *} \\
(0.032)\end{array}$ & $\begin{array}{c}-0.151 * * * \\
(0.032)\end{array}$ \\
\hline Years of education & & & & & & $\begin{array}{c}0.027 * * * \\
(0.003)\end{array}$ & $\begin{array}{c}0.026^{* * * *} \\
(0.003)\end{array}$ & $\begin{array}{c}0.024 * * * \\
(0.003)\end{array}$ & $\begin{array}{c}0.023 * * * \\
(0.003)\end{array}$ & $\begin{array}{c}0.023^{* * *} \\
(0.003)\end{array}$ & $\begin{array}{c}0.023^{* * *} \\
(0.004)\end{array}$ \\
\hline Household Income (Top 25\%) & & & & & & & $\begin{array}{c}0.085^{* *} \\
(0.038)\end{array}$ & $\begin{array}{c}0.082 * * \\
(0.038)\end{array}$ & $\begin{array}{l}0.087 * * \\
(0.038)\end{array}$ & $\begin{array}{c}0.095^{* *} \\
(0.040)\end{array}$ & $\begin{array}{c}0.120^{* *} \\
(0.057)\end{array}$ \\
\hline Retired Years & & & & & & & & $\begin{array}{l}0.001 \\
(0.002)\end{array}$ & $\begin{array}{c}0.002 \\
(0.002)\end{array}$ & $\begin{array}{c}0.002 \\
(0.002)\end{array}$ & $\begin{array}{c}0.002 \\
(0.002)\end{array}$ \\
\hline Never worked & & & & & & & & $\begin{array}{c}-0.152 * * * \\
(0.040)\end{array}$ & $\begin{array}{c}-0.125^{* * *} \\
(0.040)\end{array}$ & $\begin{array}{c}-0.117 * * * \\
(0.041)\end{array}$ & $\begin{array}{c}-0.091 * * \\
(0.044)\end{array}$ \\
\hline Health Controls & & & & & & & & & $\checkmark$ & $\checkmark$ & $\checkmark$ \\
\hline Household Characteristics & & & & & & & & & & $\checkmark$ & $\checkmark$ \\
\hline Country Fixed Effects & & & & & & & & & & & $\checkmark$ \\
\hline$R$ Squared & 0.104 & 0.356 & 0.364 & 0.364 & 0.365 & 0.376 & 0.377 & 0.380 & 0.386 & 0.387 & 0.390 \\
\hline
\end{tabular}

Notes: * significant at $10 \%$ level; ** significant at $5 \%$ level; ***significant at $1 \%$ level.

$\mathrm{n}=3798$ for all specifications

Robust standard errors clustered at household level are in parentheses and there are 3199 clusters in total.

Health controls are physical inactivity, Standardized body mass index, Standardized number of doctor visits, whether has long-term chronic disease, whether drink (more than two glasses) every day, whether smoke every day. Regression also includes controls for years retired. For those who never worked, years retired was replaced with years since reaching national statutory retirement age. Household characteristics were controls for marital status, household size, living area (urban, rural, or town), house ownership,

whether at nursing house, and Standardized total household income (transformed using PPP index). 
Table A4: First Stage Results of Instrumental Variable Estimation

\begin{tabular}{|c|c|c|c|c|}
\hline \multirow[t]{3}{*}{ First-stage Coefficients } & \multicolumn{3}{|c|}{ Whether Use Internet (2013) } & \multirow{3}{*}{$\begin{array}{l}\text { Alternative } \\
\text { Specification } \\
\text { Logit }\end{array}$} \\
\hline & All Observations & Men Only & Women Only & \\
\hline & OLS & OLS & OLS & \\
\hline \multirow[t]{2}{*}{ Used computer in final job before retirement } & $0.305 * * *$ & $0.290 * * *$ & $0.302 * * *$ & $0.169 * * *$ \\
\hline & $(0.020)$ & $(0.028)$ & $(0.031)$ & $(0.013)$ \\
\hline \multirow[t]{2}{*}{ Cognitive function (2011) } & $0.053 * * *$ & $0.068 * * *$ & $0.043 * * *$ & $0.049 * * *$ \\
\hline & $(0.007)$ & $(0.012)$ & $(0.009)$ & $(0.007)$ \\
\hline \multirow[t]{2}{*}{ Age } & -0.013 & $-0.05^{*}$ & -0.001 & -0.006 \\
\hline & $(0.013)$ & $(0.026)$ & $(0.014)$ & $(0.015)$ \\
\hline \multirow[t]{2}{*}{ Men } & $0.092 * * *$ & & & $0.085 * * *$ \\
\hline & $(0.016)$ & & & $(0.014)$ \\
\hline \multirow[t]{2}{*}{ Years of education } & $0.013 * * *$ & $0.016^{* * *}$ & $0.010 * * *$ & $0.013 * * *$ \\
\hline & $(0.002)$ & $(0.003)$ & $(0.002)$ & $(0.002)$ \\
\hline \multirow[t]{2}{*}{ Income (top 25\%) } & $0.074 * * *$ & $0.068^{*}$ & $0.074 * *$ & $0.088 * *$ \\
\hline & $(0.024)$ & $(0.040)$ & $(0.031)$ & $(0.035)$ \\
\hline \multirow{2}{*}{ Physical Inactive } & $-0.029 *$ & -0.020 & $-0.042 * * *$ & $-0.064 * * *$ \\
\hline & $(0.014)$ & $(0.026)$ & $(0.016)$ & $(0.018)$ \\
\hline \multirow[t]{2}{*}{ Household Size } & $-0.018 * *$ & $-0.026^{*}$ & $-0.015^{*}$ & $-0.032 * *$ \\
\hline & $(0.008)$ & $(0.015)$ & $(0.009)$ & $(0.013)$ \\
\hline \multirow[t]{2}{*}{ Never married } & $-0.058 * *$ & $-0.124 * * *$ & -0.012 & $-0.061 *$ \\
\hline & $(0.028)$ & $(0.046)$ & $(0.036)$ & $(0.032)$ \\
\hline \multirow[t]{2}{*}{ Suburbs of big cities } & $0.072 * * *$ & $0.085 * * *$ & $0.054^{*}$ & $0.071 * * *$ \\
\hline & $(0.022)$ & $(0.032)$ & $(0.028)$ & $(0.020)$ \\
\hline$R$-squared & 0.383 & 0.357 & 0.318 & 0.334 \\
\hline$n$ & 3798 & 1717 & 2081 & 3786 \\
\hline
\end{tabular}

Notes: * significant at $10 \%$ level; ** significant at $5 \%$ level; ***significant at $1 \%$ level.

Cluster robust standard errors are in parentheses.

Regressions also include other controls that are similar in our main specification, and this Table only presents a few selected factors of interest.

The column of estimated Logit model reports average marginal impact. 
Figures

Figure 1: Internet Usage in Subgroups
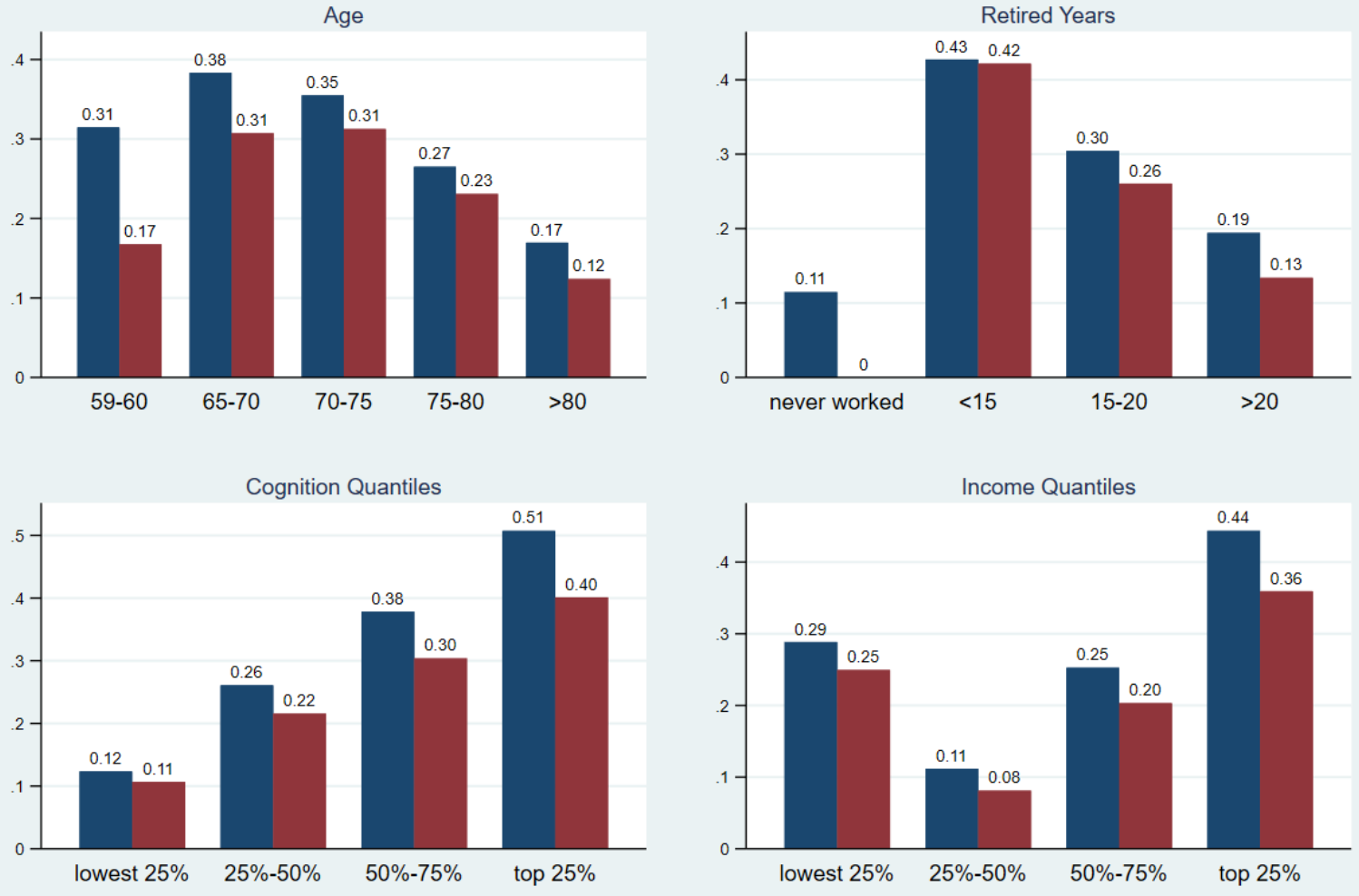

current internet use

computer use in the final job 
Figure 2: ICT use by Industry

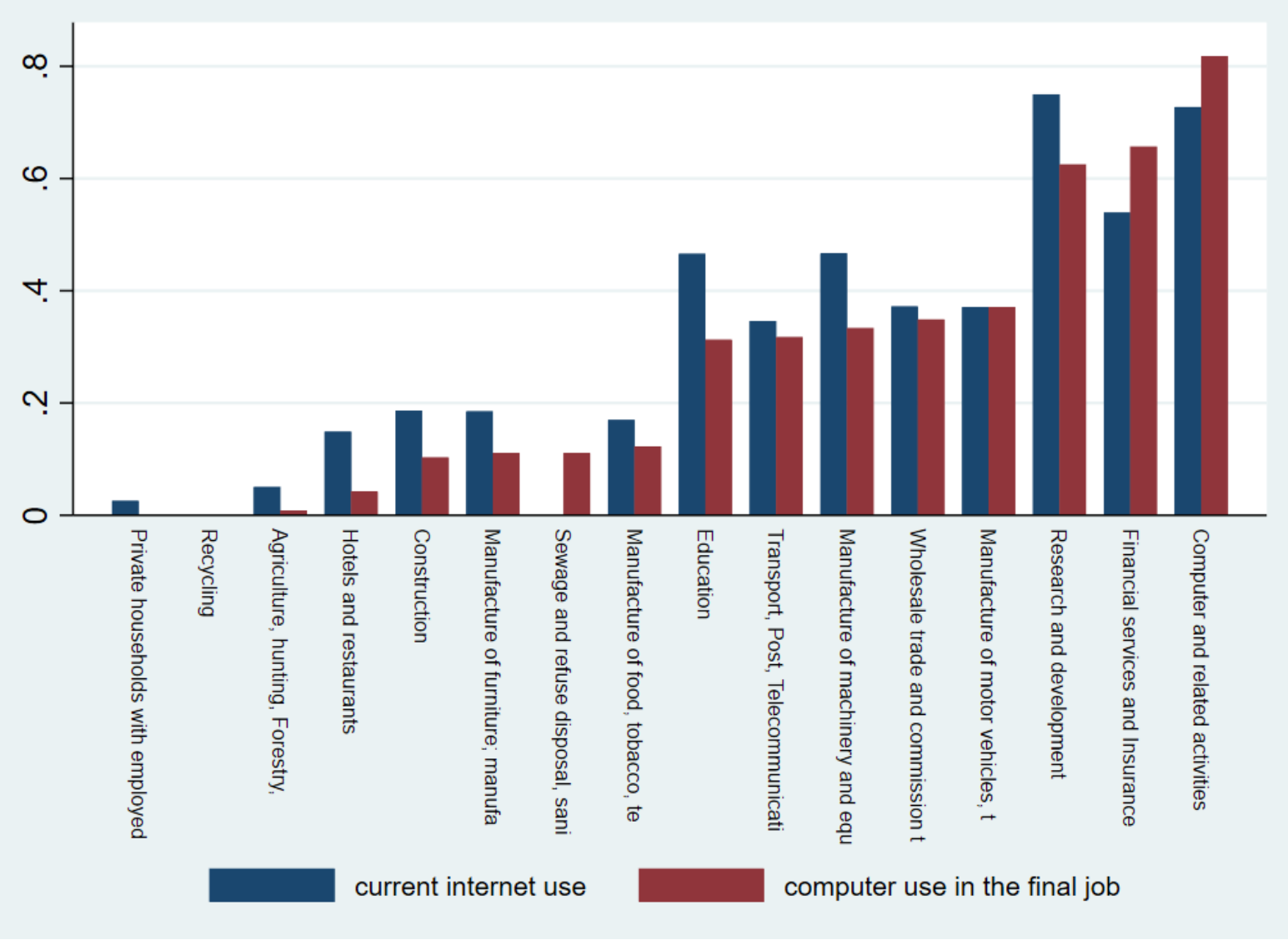

Note: Sorted by the pc use in the final job before retirement. 


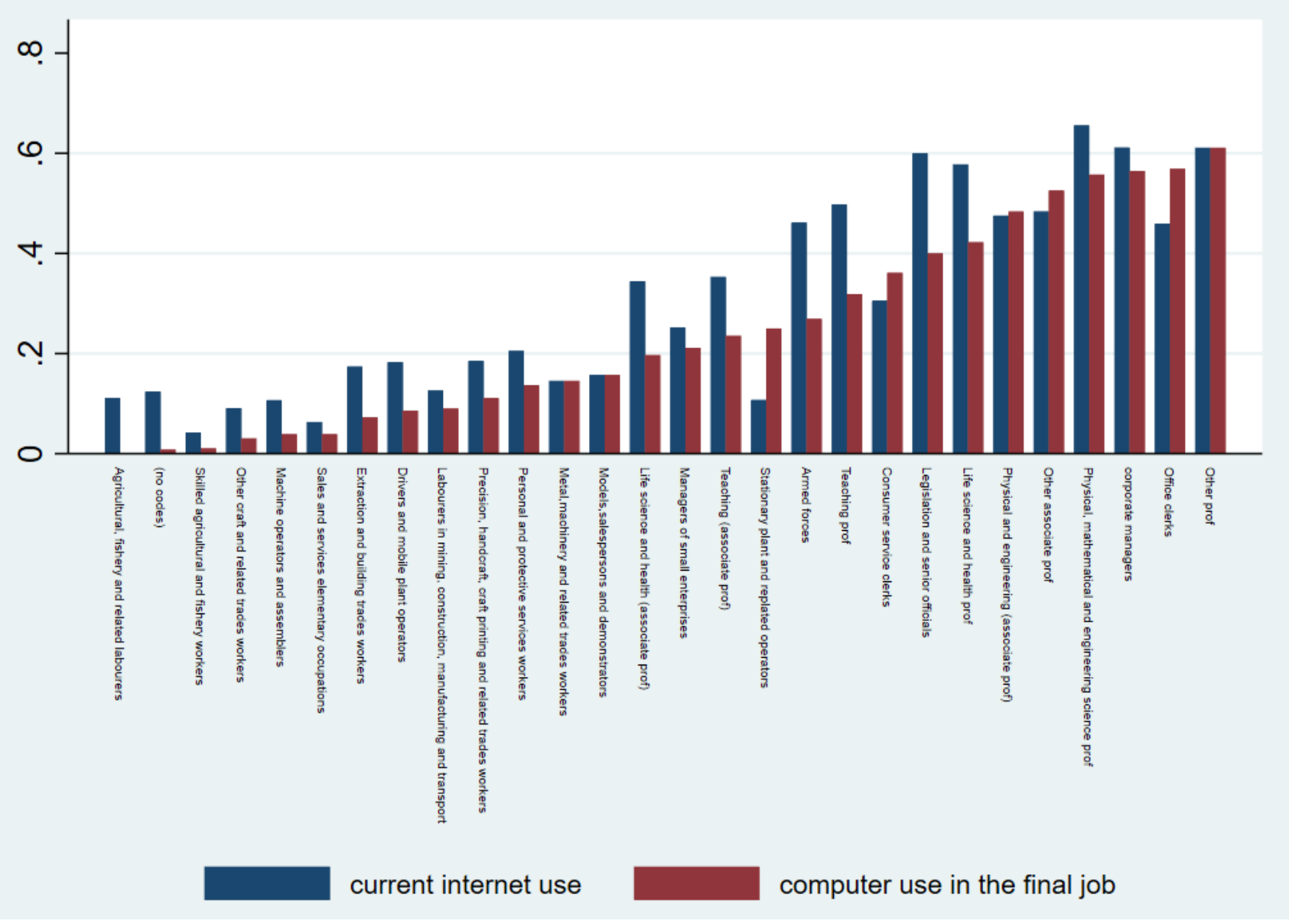

Note: Sorted by the computer usage in the final job before retirement. 